\title{
Intestinal Parasitic Helminths of Rattus spp. in Caspian Sea Littoral, Iran
}

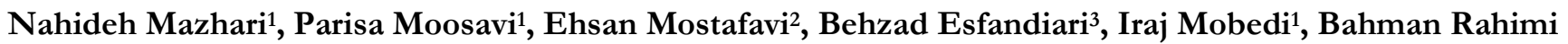

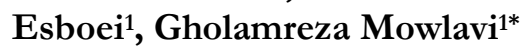

\begin{abstract}
${ }^{1}$ Department of Medical Parasitology and Mycology, School of Public Health, Tehran University of Medical Sciences, Tehran, Iran; ${ }^{2}$ Department of Epidemiology and Biostatistics, Research Centre for Emerging and Reemerging Infectious Diseases, Pasteur Institute of Iran, Tehran, Iran; ${ }^{3}$ Laboratory of Animal Sciences, Pasteur Institute of Iran, Tehran, Iran
\end{abstract}

Received Jul. 01, 2018; Accepted Jul. 07, 2018

\begin{abstract}
Introduction: Rodents are known as the reservoir of various zoonotic diseases and play a critical role in the transmission of pathogenic agents to humans. During an investigation on rodent reservoirs of leptospirosis in Caspian Sea littoral, northern Iran, we took advantage of the opportunity to examine the animals for intestinal helminth infections. Methods: We received gastrointestinal tracts (GITs) of 132 rodents belonged to the genus Rattus, from Mazandaran, Gilan and Golestan Provinces. The GIT of the animals had been preserved in 10\% formalin and transferred to Helminthology Laboratory of School of Public Health, Tehran University of Medical Sciences. We examined the GITs contents for helminths under a binocular followed by a microscope with different magnifications and identified the specimens according to reliable morphological keys. Results: Out of the 132 rats, $83(62.87 \%)$ harbored helminth parasites. We identified 11 helminth species among which the zoonotic cestodes, Hymenolepis diminuta (29.5\%) and Hymenolepis nana (18.18\%) exhibited the highest prevalence. The species Euparyphium murinum and Skerjabinotaenia abnormalis are reported here for the first time from Iran. Conclusion: The Caspian Sea littoral of Iran is a suitable area for the breeding of the commensal rodents. In this study, the rats from this area exhibited a high burden of helminth infections, with some species of public health importance. J Med Microbiol Infec Dis, 2019, 7 (1-2): 32-36.
\end{abstract}

Keywords: Rattus spp., Intestinal parasites, Caspian Sea, Iran.

\section{INTRODUCTION}

Some rodent species, referred to as commensal rats, thrive near humans. This proximity makes quick access to their vital needs, such as food and habitat [1, 2]. Many rodents are known as the primary reservoir of some lifethreatening pathogens, and along with the arthropods that infest the animals, e.g., fleas, lice, play a critical role in spreading pathogenic agents [2]. Some species of rodents harbor parasite of public health importance such as leishmaniasis, toxoplasmosis, babesiosis, and hymenolepiasis [3, 4], among which some zoonoses such as leishmaniasis and toxoplasmosis are regarded as the most harmful parasites to humans especially in immunocompromised individuals [5]. Human infection with some parasites like Hymenolepis nana occurs through accidental ingestion of foods and drinking water contaminated with rodent droppings containing the parasite eggs [6-8]. The diversity of parasite fauna in rodents species and infection rates depend on the environmental and geographical conditions [9-12]. In commensal species like Rattus rattus and Rattus norvegicus, human behaviors and their leftovers are critical factors. Caspian Sea littoral in the north of Iran with temperate weather and dense vegetations has provided suitable habitats for commensal rodents such as rats $[13,14]$. This area is also endemic for leptospirosis [15]. An investigation of rodent reservoir host of leptospirosis in Caspian Sea littoral provided us the opportunity to investigate the helminthic infections among these animals in this area.

\section{MATERIAL AND METHODS}

The study area comprised parts of three provinces in Northern Iran, Gilan, Mazandaran, and Golestan (Fig. 1). In 2014, we received gastrointestinal tracts (GITs) of 132 rodents belonging to the genus Rattus. The animals were captured by live traps during an investigation of rodent reservoirs of leptospirosis in Caspian sea littoral, i.e., Mazandaran, Gilan and Golestan Provinces. The rodents have been identified onsite based on morphological features. The GIT of animals were preserved individually in $10 \%$ formalin and transported to the Helminthology Laboratory of School of Public Health, Tehran University of Medical

*Correspondence: Gholamreza Mowlavi

Department of Medical Parasitology and Mycology, School of Public Health, Tehran University of Medical Sciences, Tehran, Iran, 141556446.

Email: molavig@yahoo.com

Tel/Fax: +98 (21) 88951392 
Sciences. We cut the upper and lower parts of GITs longitudinally and examined their contents for helminths under a binocular and a microscope with different magnifications. The recovered helminths were stained with Azocarmine Lactophenol, and the drawings with measurements were prepared under an equipped camera lucida microscope. The helminths were identified based on morphology and morphometric features reflected in the valid taxonomic keys [16-18]. Also, the formalin-ether sedimentation technique was performed on intestinal contents, and wet smears were prepared and examined for the presence of helminths egg under a light microscope with magnifications $100 \mathrm{X}$ to $400 \mathrm{X}$.

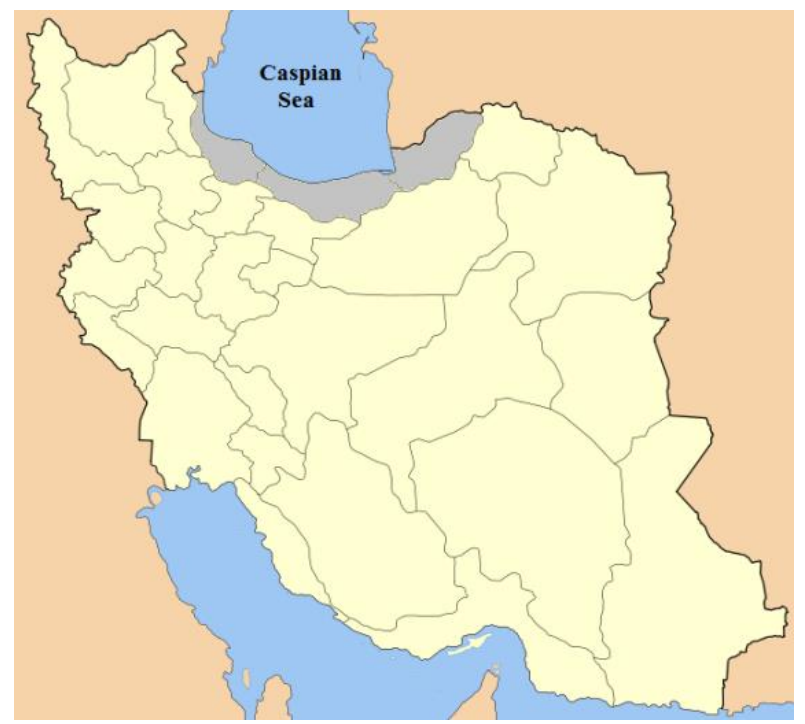

Fig. 1. Map of Iran, the study area in gray shows Gilan, Golestan, and Mazandaran Provinces

\section{RESULTS}

Rodent species. In this survey, we examined 54 rats from Gilan, 36 from Mazandaran, and 42 from Golestan Provinces. All the animals belonged to the genus Rattus and included $58.3 \%$ males and $41.7 \%$ females. Due to the onsite identification of the animals, the accurate identification of the specimens at the species level was not possible.

Helminth infections. Out of the 132 rats examined, 83 $(62.87 \%)$ had helminth parasites, among which $75 \%$ harbored zoonotic helminths of public health importance. Eleven helminths species were identified including seven nematodes (Heterakis spumosa, Syphacia muris, Syphacia obvelata Trichuris muris, Streptopharagus kuntzi, Aspicularis tetrapetra, and Capillaria annulosa), three cestodes (Hymenolepis diminuta, Hymenolepis nana, and
Skerjabinotaenia abnormalis) and one trematode (Euparyphium murinum) (Figs. 2 and 3). The cestodes showed the highest prevalence $(48.48 \%)$, and the zoonotic H. diminuta $(29.5 \%)$, and $H$. nana $(18.18 \%)$ were the most common species. The prevalence of other helminths were $H$. spumosa (25\%), S. muris (13.63\%), T. muris (3.76\%), S. kuntzi $(2.27 \%)$, A. tetrapetra (1.51\%), E. murinom (1.51\%), $S$. abnormalis and C. annulosa $(0.75 \%)$ (Table 1$)$. In this study, we report E. murinom and S. abnormalis for the first time from Iran. Among the infected rats, 58 (69.87\%) harbored one helminth species, 24 (28.91\%) and $1(1.20 \%)$ animals showed coinfection with two and three species, respectively. The formalin-ether sedimentation technique merely revealed only the eggs of $H$. nana.

Table1. The helminths recovered from Rats in Gilan, Mazandaran and Golestan Provinces, northern Iran

\begin{tabular}{|c|c|c|c|c|}
\hline \multirow{2}{*}{ Parasite species } & \multicolumn{3}{|c|}{ No. of infected rodents in different Provinces (\%) } & \multirow{2}{*}{ Infection rate $(\%)$} \\
\hline & Gilan & Mazandaran & Golestan & \\
\hline H. nana & $11(20.37 \%)$ & $11(30.55 \%)$ & $2(4.76 \%)$ & $24(18.18 \%)$ \\
\hline H. diminuta & $18(33.3 \%)$ & $7(19.4 \%)$ & $14(33.3 \%)$ & $39(29.54 \%)$ \\
\hline H. spumosa & $22(40.74 \%)$ & $7(19.4 \%)$ & $4(9.52 \%)$ & $33(25 \%)$ \\
\hline C. annulosa & $1(1.85 \%)$ & 0 & 0 & $1(0.75 \%)$ \\
\hline S. obvelata & $6(11.11 \%)$ & $6(16.6 \%)$ & $4(9.52 \%)$ & $18(13.63 \%)$ \\
\hline S. muris & $2(3.70 \%)$ & 0 & 0 & $2(1.51 \%)$ \\
\hline A. tetraptera & $1(1.85 \%)$ & 0 & 0 & $1(0.75 \%)$ \\
\hline T. muris & $4(7.4 \%)$ & 0 & $1(2.38 \%)$ & $5(3.78 \%)$ \\
\hline S. kuntzi & $1(1.85 \%)$ & 0 & $2(4.76 \%)$ & $3(2.27 \%)$ \\
\hline S. abnormalis & $1(1.85 \%)$ & 0 & $1(2.38 \%)$ & $1(0.75 \%)$ \\
\hline E. murinom & 0 & $2(5.55 \%)$ & 0 & $2(1.51 \%)$ \\
\hline Total Infected rodents & $40(74.07 \%)$ & $23(63.88 \%)$ & $20(47.61 \%)$ & \\
\hline Zoonotic & $68.47 \%$ & $66.57 \%$ & $47.58 \%$ & \\
\hline
\end{tabular}




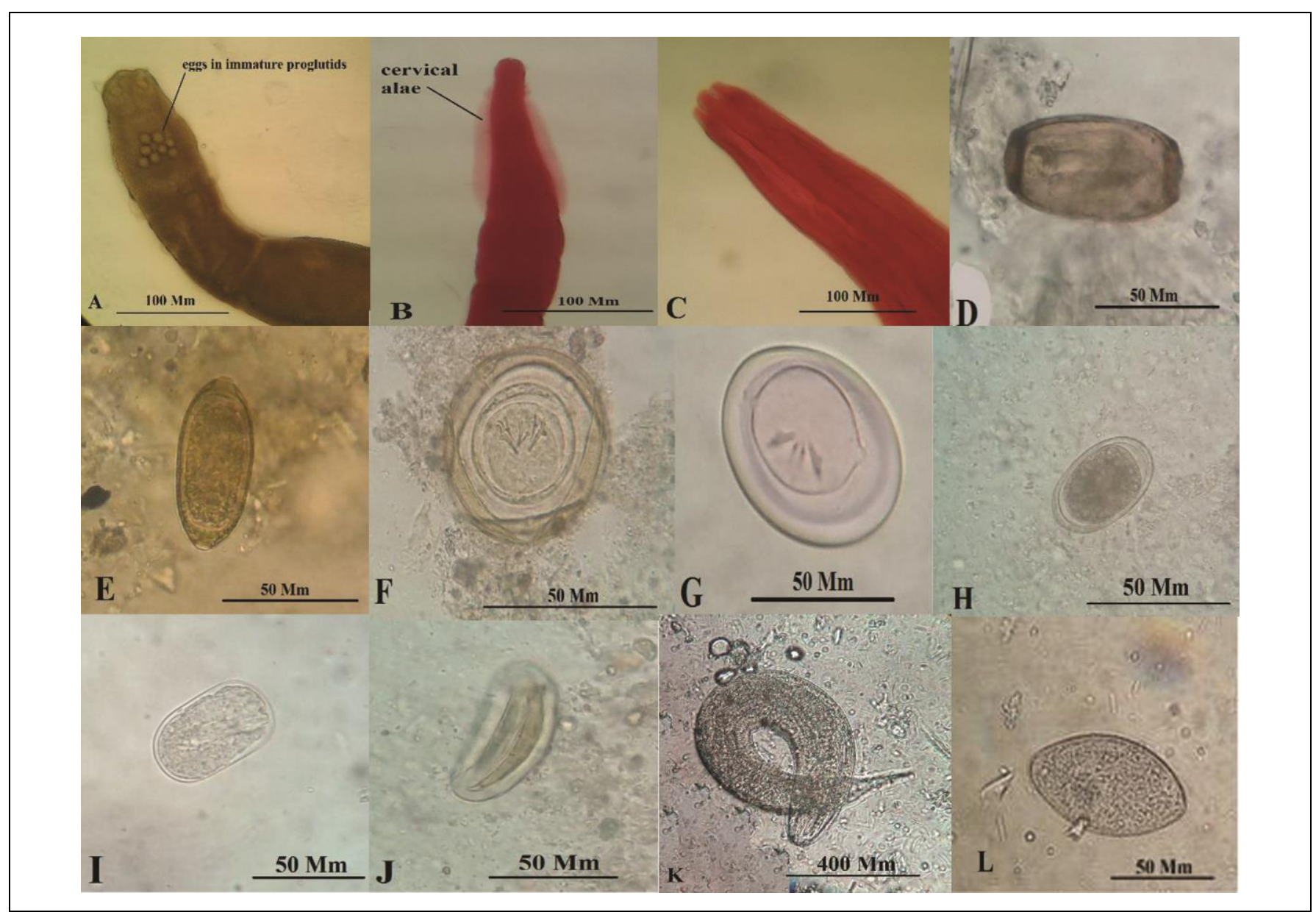

Fig. 2. The intestinal helminths species identified in the gastrointestinal contents of the Rattus spp. from Caspian Sea littoral, northern Iran (magnification 400X). (A) the anterior end of $S$. abnormalis, (B) the cervical alae of A. tetraptera, (C) the anterior end of $S$. kuntzi, (D) C. annulosa egg. (E) T. muris egg, (F) H. diminuta egg, (G) H. nana egg, (H) S. kuntzi egg, (I) H. spumosa egg, (J) S. obvelata egg, (K) S. muris larva; (L) S. muris egg.

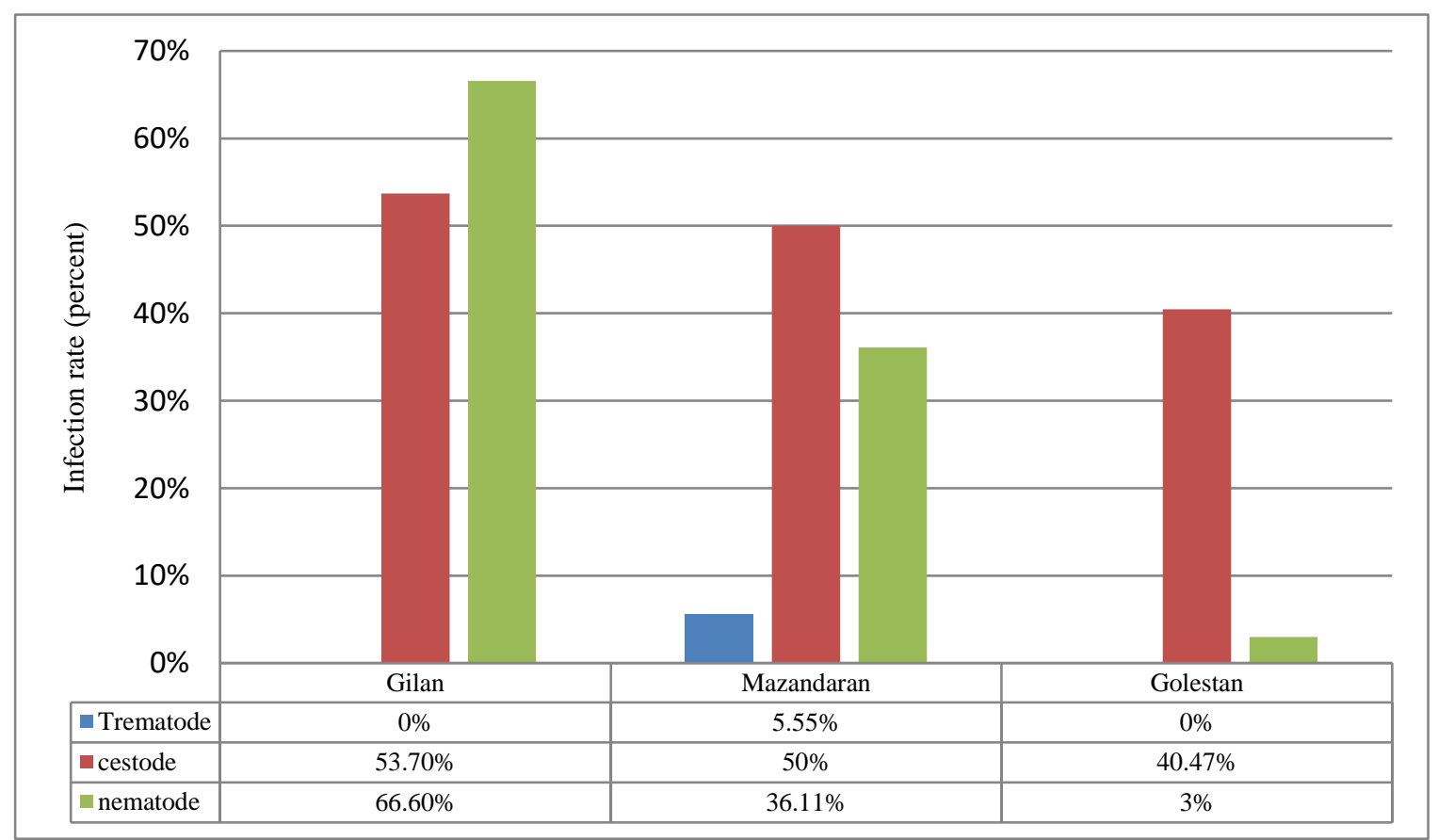

Fig. 3. Prevalence of trematodes, cestodes, and nematodes in rats of Gilan, Mazandaran and Golestan Provinces, northern Iran 


\section{DISCUSSION}

Some rats live in close association with humans and take the advantages of urban environments such as food and shelter [7]. There is evidence that human disturbance of the ecosystem like forest clearing is providing new habitat for commensal rodents [2]. In our study, Rattus spp. was the most dominant entrapped rodents in the studied area. The results of this study revealed an infection rate of $74.07 \%$ in rats of Gilan province, and $63.88 \%$ and $47.61 \%$ in rats of Mazandaran and Golestan provinces, respectively. We identified a relatively wide range of intestinal helminths in the rat specimens, and the zoonotic species $H$. nana and $H$. diminuta were the most prevalent helminths. In Iran, human infection of $H$. nana is still prevalent, and reports of this helminth infection are available from different parts of the country like Kermanshah, Semnan, Ahvaz, and Hormozgan, while $H$. diminuta rarely infects humans [19]. Previously, a similar study on $R$. rattus of Mazandaran Province revealed a helminth infection rate of $47.3 \%$ comprising four species with the H. nana, as the most prevalent worm (9.4\%) [17]. In our study, the infection rate with $H$. nana was much higher $(30.55 \%)$ in this animal, which is close to the result of a report from Tehran, where the $H$. nana infection rate in $R$. rattus was reported to be $35.8 \%$ [7]. The infection rate with trematodes was relatively low, and only the two animals from Mazandaran Province had an infection with a single E. murinom fluke. Infection of rats with this trematode can be an indication of suitable weather conditions for the presence of the intermediate snail hosts [14]. Previous studies in Caspian Sea littoral demonstrated a high helminthic infection rate among wild rodents. In Maraveh Tappeh of Golestan Province, of 77 Rhombomys opimus specimens, $81.8 \%$ were naturally infected with various helminth species [11], and the 5.2\% prevalence of $H$. nana infections among them was approximately similar to the rate $(4.76 \%)$ we found here in rats. Examination of rodents ( $R$. rattus, $R$. norvegicus, and Mus musculus) in Kermanshah revealed helminths species similar to our findings. The survey reported $T$. muris as the most prevalent species, and surprisingly no infection of $H$. nana, the most prevalent zoonotic helminth of Iran [20]. The rat tapeworm, $H$. diminuta, is primarily a parasite of rats and rarely infect humans. In Iran, there are reports of $H$. diminuta human infections from Mashhad and the area along the Persian Gulf, with the highest infection rate in Minab of Hormozgan Province [21, 22]. Infection with this worm is usually asymptomatic, but in some cases, mild diarrhea, abdominal pain, irritability, pruritus, and eosinophilia were among the symptoms [21-23]. In the present survey, this zoonotic helminth was the most prevalent species in rats of Gilan and Golestan Provinces. Our findings are in agreement with the results of the similar studies in Ardabil and Hamadan, where $H$. diminuta was the most prevalent intestinal parasite in $R$. norvegicus and Meriones persicus [10, 24]. Although the parasites such as $H$. diminuta are highly expected to be carried by rats, some other rodent species might harbor them as well. In our study, the rodents were identified on-site; hence, there might be chances that some animals were misidentified for the members of the genus Rattus. In the present study, the high prevalence rate of $H$. nana and $H$. diminuta among the rodents might be attributed to the favorable climatological and environmental condition in the Caspian Sea littoral, which facilitates the survival of parasite eggs in the environment.

Our study demonstrated a heavy burden of helminths infection among rats in Caspian Sea littoral that comprised 11 species. The high prevalence of zoonotic helminths of public health concern, e.g., $H$. diminuta and $H$. nana reflect the pivotal role of rats in spreading these parasitic agents.

\section{ACKNOWLEDGMENT}

The rodent samples belonged to the Ph.D. thesis project of Dr. Behzad Esfandiari on reservoirs of leptospirosis in Caspian Sea littoral. The authors would like to thank Mr. Hamed Hanifi from Pasteur Institute of Iran for his enthusiastic collaboration, and the colleagues in the Laboratory of Helminthology, School of Public Health, Tehran University of Medical Sciences for their technical assistance.

\section{CONFLICT OF INTEREST}

The authors declare that there are no conflicts of interest associated with this manuscript.

\section{REFERENCES}

1. Coomansingh C, Pinckney R, Bhaiyat M, Chikweto A, Bitner $\mathrm{S}$, Baffa A, et al. Prevalence of endoparasites in wild rats in Grenada. West Ind Vet J. 2009; 9 (1): 17-21.

2. Stenseth NC, Leirs H, Skonhoft A, Davis SA, Pech RP, Andreassen HP, et al. Mice, rats, and people: the bio-economics of agricultural rodent pests. Front Ecol Environ. 2003; 1 (7): $367-75$.

3. Paramasvaran S, Sani RA, Hassan L, Hanjeet K, Krishnasamy M, John J, et al. Endo-parasite fauna of rodents caught in five wet markets in Kuala Lumpur and its potential zoonotic implications. Trop Biomed. 2009; 26 (1): 67-72.

4. Weiss LM. Zoonotic parasitic diseases: emerging issues and problems. Int J Parasitol. 2008; 38 (11): 1209.

5. Alvar J, Aparicio P, Aseffa A, Den Boer M, Cañavate C, Dedet J, et al. The relationship between Leishmaniasis and AIDS: the Second 10 Years. Clin Microbiol Rev. 2008; 21 (2): 334-59.

6. Ito M, Itagaki T. Survey on wild rodents for endoparasites in Iwate Prefecture, Japan. J Vet Med Sci. 2003; 65 (10): 1151-3.

7. Meshkekar M, Sadraei J, Mahmoodzadeh A, Mobedi I. Helminth infections in Rattus ratus and Rattus norvigicus in Tehran, Iran. Iran J Parasitol. 2014; 9 (4): 548.

8. Singla LD, Singla N, Parshad VR, Juyla PD. Rodents as reservoirs of parasites in India. Integr Zool. 2008; 3: 21-6.

9. Rasti S, Mobedi I, Dehghani R, Doroudghar A, Arbabi M. Epidemiology of intestinal parasites in rodents of urban and rural areas in Kashan. Feyz. 2002; 5 (4): 102-8. 
10. Kia E, Shahryary-Rad E, Mohebali M, Mahmoudi M, Mobedi I, Zahabiun F, et al. Endoparasites of rodents and their zoonotic importance in Germi, Dashte-Mogan, Ardabil Province, Iran. Iran J Parasitol. 2010; 5 (4): 15-20.

11. Kamranrashani B, Kia E, Mobedi I, Mohebali M, Zarei Z, Mowlavi G, et al. Helminth Parasites of Rhombomys opimus from Golestan Province, Northeast Iran. Iran J Parasitol. 2013; 8 (1): 78-84.

12. Kia E, Homayouni M, Farahnak A, Mohebali M, Shojai S. Study of endoparasites of rodents and their zoonotic importance in Ahvaz, southwest Iran. Iranian J Publ Health. 2001; 30 (1-2): 49-52.

13. Sedaghat M, Salahi Moghaddam A. Mapping the distribution of the important rodents reservoir in Iran. JAUMS. 2010; 8 (3): 210-23.

14. Gholami S, Motevalli-Haghi F, Mobedi I, Shahabi S. Study of intestinal helminth parasites of rodents in urban areas of Mazandaran province. J Mazandaran Univ Med Sci. 2003; 12 (35): 67-73 [In Persian].

15. Vahid G, Naddaf SR, Aghighi Z, Hassan N, Pooya M, Mostafavi E. Leptospirosis in Caspian Sea littoral, Gilan Province, Iran. Acta Tropica. 2018; 181: 11-15.

16. Skrjabin KI. Key to Parasitic Nematodes, Vol. I. Moscow: Academy of Sciences. USSR; 1969 [In Russian].

17. Skrjabin KI, Shikhobalova NP, Mozgovoi AA. Suborder Ascaridata Skrjabin, 1915. In: Skrjabin KI (ed) Key to parasitic nematodes: Amerind, New Delhi; 1991. 423-595.
18. Yamaguti S. Systema Helminthum, Vol. 3. The Nematodes of Vertebrates. New York: Interscience Publishers; 1961.

19. Rokni M. The present status of human helminthic diseases in Iran. Ann Trop Med Parasitol. 2008; 102 (4): 283-95.

20. Pakdel N, Naem S, Rezaei F, Chalehchaleh A-A, editors. A survey on helminthic infection in mice (Mus musculus) and rats (Rattus norvegicus and Rattus rattus) in Kermanshah, Iran. Veterinary Research Forum; 2013: Faculty of Veterinary Medicine, Urmia University, Urmia, Iran.

21. Ghadirian E, Arfaa A. Human infection with Hymenolepis diminuta in villages of Minab, South Iran. Int J Parasitol. 1972; 2 (4): 481-2.

22. Mowlavi G, Mobedi I, Mamishi S, Rezaeian M, Haghi Ashtiani M, Kashi M. Hymenolepis diminuta (Rudolphi, 1819) infection in a child from Iran. Iranian J Public Health. 2008; 37 (2): $120-1$.

23. Tena D, Simón MP, Gimeno C, Pomata MTP, Illescas S, Amondarain I, et al. Human infection with Hymenolepis diminuta: case report from Spain. J Clin Microbiol. 1998; 36 (8): 2375-76.

24. Moradi M, Matini M, Mohemi N, Maghsoudnia A, Zahirnia A, Mohammad F. Study of zoonotic intestinal helmiths of alimentary tract of rodents in Hamadan, 2012. Med Lab J. 2015; 9 (2): 103-9. 